\title{
Referees 2010
}

(c) Springer-Verlag 2010

The Editor-in-chief is grateful to the following colleagues for generously giving their time in careful evaluation of manuscripts submitted to RHEUMATOLOGY INTERNATIONAL in 2010!

Without this help and scientific background the publication of this journal would not have been possible. This is even more valuable, since in the thirtiest year on the market, the number of incoming submissions is steadily increasing to a record in 2010 (about $25 \%$ higher than in 2009!)

Thus: Great appreciations to our reviewers, but the same amount of thanks goes to our author, too!

$\begin{array}{llll}\text { Olaf Manfred Adam } & \text { München } & \text { Ozgur Kasapcopur } & \text { Istanbul } \\ \text { Christoph G.O. Baerwald } & \text { Leipzig } & \text { Herbert Kellner } & \text { München } \\ \text { Johannes Beckmann } & \text { Bad Abbach } & \text { Ina Kötter } & \text { Tübingen } \\ \text { Claudia Berek } & \text { Berlin } & \text { Jens Gert Kuipers } & \text { Bremen } \\ \text { Hans-Peter Brezinski } & \text { Graz } & \text { Sevdalina Nikolova Lambova } & \text { Plovdiv } \\ \text { Jürgen Bunner } & \text { Insbruck } & \text { Ernst-Martin Lemmel } & \text { Baden-Baden } \\ \text { Gulsen-Akman Demir } & \text { Istanbul } & \text { Hanns-Martin Lorenz } & \text { Heidelberg } \\ \text { R. Dinser } & \text { Hombueg } & \text { Bernhard Manger } & \text { Erlangen } \\ \text { Haner Direskeneli } & \text { Istanbul } & \text { Wilfried Mau } & \text { Halle/Saale } \\ \text { Thorsten Eidner } & \text { Jena } & \text { Inga Melchers } & \text { Freiburg } \\ \text { Ludwig Erlach } & \text { Wien } & \text { Brigitte Müller-Hilke } & \text { Rostock } \\ \text { Ernst Feldtkeller } & \text { München } & \text { Peter Oelzner } & \text { Jena } \\ \text { Ivan Foeldvari } & \text { Hamburg } & \text { Johann D. Ringe } & \text { Leverkusen } \\ \text { Armen Yuri Gasparyan } & \text { Yerevan } & \text { Michael Schirmer } & \text { Insbruck } \\ \text { Hermann Girschick } & \text { Würburg } & \text { Klaus L. Schmidt } & \text { Bad Nauheim } \\ \text { Susanne Graessel } & \text { Regensburg } & \text { Hendrik Schulze-Koops } & \text { Erlangen } \\ \text { Joachim Grifka } & \text { Bad Abbach } & \text { Ulrich Christian Smolenski } & \text { Jena } \\ \text { W.L. Gross } & \text { Bad Bramstedt } & \text { K. Spesshardt } & \text { Karlsbad } \\ \text { Johannes Peter Haas } & \text { Greifswald } & \text { B. Swoboda } & \text { Erlangen } \\ \text { Manfred Herold } & \text { Insbruck } & \text { I. Tarner } & \text { Bad Nauheim } \\ \text { Martin Herrmann } & \text { Erlangen } & \text { Hasan Yazici } & \text { Istanbul } \\ \text { Gerd Horneff } & \text { St. Augustin } & & \\ \text { Hans-Iko Huppertz } & \text { Bremen } & & \\ \text { Wilfried H. Jaeckel } & \text { Bad Säckingen } & & \\ & & & \end{array}$

